\title{
A series of foundation phase dictionaries for a multilingual environment
}

\author{
Rufus H. Gouws \\ Department of Afrikaans and Dutch, University of Stellenbosch, South Africa \\ Email: rhg@sun.ac.za \\ Danie J. Prinsloo \\ Department of African Languages, University of Pretoria, South Africa \\ Email: danie.prinsloo@up.ac.za \\ Mawande Dlali \\ Department of African Languages, University of Stellenbosch, South Africa \\ Email: mdl@sun.ac.za
}

\begin{abstract}
The aim of this article is to reflect on the design and use of the Maskew Miller Longman series of dictionaries published in several different official languages of South Africa and aimed at learners in the foundation phase of primary school. It will be argued that when planning new dictionaries such as these, lexicographers should have the user perspective as point of departure by compiling user-friendly dictionaries suitable for the level of first-time dictionary users. Lexicographers should furthermore negotiate the position of the envisaged dictionary within a broader family of dictionaries - an approach that sees dictionary use as an integral part of a process of life-long learning, thereby establishing and promoting a dictionary culture.
\end{abstract}

Keywords: foundation phase dictionaries, dictionary functions, dictionary culture, frame structure of dictionaries

\section{Introduction}

One of the recent developments in lexicographic practice has been a change in the approach to traditional typological classifications. Earlier theoretical work gave a clear indication of different typological categories (cf. Zgusta 1971) and, in the planning and compilation of new dictionaries, lexicographers usually adhered to these categories by producing dictionaries that complied with the criteria devised for the relevant typological category. Dictionaries therefore displayed the typical features associated with the specific dictionary type. 
The user perspective that has dominated the lexicographic work on both practical and theoretical levels during the last two decades has also had an influence on the approach to typological classification. In recent years, there has been a shift from a typology-directed approach to one that is more user-directed in the planning and compilation of new dictionaries (cf. e.g. Gouws 2006, 2007). A question any lexicographer has to answer with regard to a new dictionary project is no longer to which typological category the dictionary should belong, but rather what the lexicographer wants the intended target user to be able to do with the specific dictionary; this will determine the typological classification of the dictionary.

Recent metalexicographic discussions also focused on issues regarding some traditional categories, e.g. the category of school dictionaries (cf. Tarp and Gouws 2010, 2012, and Tarp and Miyares 2013). One of the aspects that came to the fore in these discussions is the need for a much more refined look at so-called "school dictionaries". A classification like "school dictionary" is much too blunt and does not make provision for the diverse needs of a broad spectrum of users with different needs and diverse dictionary-utilisation skills. Furthermore, different target-user age groups have to be taken into account while being mindful of the different functions these dictionaries need to fulfill, the fact that some dictionaries are monolingual whereas others are bilingual and that some are directed at mother-tongue speakers whereas others are directed at users that have the treated language as a second or additional language.

When looking at different age groups, the curriculum of the respective grades needs to be negotiated in order to decide on the contents and presentation of data in a given dictionary. In this regard, a dictionary like Nuwe Woordeboek Sonder Grense (Gouws, Stark and Gouws 2004) was directed specifically at users in grades four to six with Afrikaans as their third or fourth language. The lemma selection and contents were determined by the contents of the relevant curricula and the guidelines set by educators.

The new political dispensation in South Africa introduced 11 official languages, namely Afrikaans, English, IsiNdebele, IsiXhosa, IsiZulu, Sepedi, Sesotho, Setswana, SiSwati, Tshivenda and Xitsonga. The Pan South African Language Board (PanSALB) was established to oversee the implementation and execution of the new language policy. As a result, 11 national lexicography units (NLUs), managed under the auspices of PanSALB, were established with the brief to compile dictionaries for all the official languages. The emergence and early activities of the NLUs unfortunately brought to light the fact that most South African languages had generations of speakers unfamiliar with dictionaries and methods of lexicographic compilation. In Hausmann's (1989) terms, there was and still is a lack of a "dictionary culture". A dictionary culture prevails where a speech community adapts to lexicography, i.e. where the speakers acquire the necessary dictionary-using skills to know when to use which dictionary and how to use it to ensure successful dictionary consultation.

Various problems, e.g. financial, logistical, management and administrative problems, in the NLUs and insufficient progress in responding to the needs of the different speech communities put the responsibility on commercial publishers to continue providing dictionaries to satisfy the needs of different user groups with different needs and reference skills. The last two decades witnessed the publication of a variety of dictionaries by different commercial publishing houses. An interesting aspect in this regard is a focus on non-traditional user groups, e.g. 
second-language speakers as well as new subcategories of school dictionaries, e.g. for users of different age groups.

An important motivation in the planning of new subcategories of school dictionaries is an attempt to avoid any further lexicographically lost generations by providing learners with dictionaries from the earliest possible phase to assist them in their daily scholarly activities. Publishing houses like Oxford University Press, Pharos and Maskew Miller Longman embarked on the compilation of dictionaries directed at junior primary school and foundation phase learners, among others.

In this paper the emphasis will be on foundation phase dictionaries, with special reference to the series published by Maskew Miller Longman, and with differentiation between four of the dictionaries in this series, i.e. MML Afrikaans/English (Gouws, Potgieter and Burgess 2010), MML isiXhosa/English (Dlali 2010), MML Sepedi/English (Mabule 2010) and MML Setswana/English (Ramagoshi 2010), where required in the following discussion.

\section{The lexicographic context of the series of foundation phase dictionaries}

In order to meet the lexicographic needs of a new generation of South African learners, the publishing house Maskew Miller Longman (MML) decided to launch a series of dictionaries in different official languages which are aimed at learners in the foundation phase of primary school. When working with a spectrum of dictionary types, it is a well-known fact - at least in lexicographic circles - that no single dictionary can be everything for everyone. This holds true not only in the case of a traditional typological approach, but also in the case of an approach characterised by being directed at specific target users, their needs and reference skills. Each dictionary has to be considered as part of the broader family of dictionaries and not as isolated products. One should also acknowledge that different types of dictionaries share certain features, leading to a significant overlap between neighbouring types, e.g. monolingual school, standard and comprehensive dictionaries. When planning a new dictionary, lexicographers should negotiate the position of the envisaged dictionary within a broader family of dictionaries, even if the other members of the family have not yet been compiled. Although the focus in this paper is on MML's series of foundation phase dictionaries, it is important to indicate at this stage where they belong within this broader family of dictionaries.

Dictionaries are practical tools and should be planned and used accordingly. Each dictionary should have a genuine purpose (cf. Wiegand 1998). According to Gouws (2001), the "genuine purpose of a dictionary implies that a dictionary is produced so that the target user who uses the dictionary in a typical usage context will have an instrument to assist [him/her] in achieving a successful dictionary consultation procedure by reaching the goals that motivated the search". The genuine purpose can only be achieved if the user consults a dictionary that is directed at his/her specific needs and that is compiled in accordance with the lexicographic needs and reference skills of that specific user. The diverse needs of different age and user groups determine that different dictionaries with different genuine purposes are needed.

For decades, there have been a number of so-called "school dictionaries" available for some, but not all, of the South African languages. As indicated earlier, the term "school dictionary" bluntly refers to a broad category that can hardly be accommodated in any single dictionary. The traditional South African school dictionaries often had no explicit reference to a specific 
age group, even though a vague indication like "junior" may have been included in the title, or the preface may have given an indication that the dictionary was suited for users from, for example, the age of eight years and older. Tarp and Gouws (2010) discuss this lack of a clear indication of target users and of the functions of Afrikaans school dictionaries; their discussion may also extend to school dictionaries in other South African languages.

Given the vague indication of target user groups, it could be argued that foundation phase learners in need of lexicographic assistance may as well consult a general school or junior school dictionary. However, these dictionaries do not make provision for the curriculumspecific needs or the limited dictionary-using skills of foundation phase learners. In this regard, the practical situation of dictionary use gives some interesting evidence: results of user studies in De Schryver and Prinsloo (2011) indicate that users prefer to consult a dictionary compiled for a user group one level lower than themselves. Users do not opt for a dictionary directed at a higher level of usage. The previously-mentioned Nuwe Woordeboek Sonder Grense was compiled for learners in grades 4 to 6 with Afrikaans as a third or fourth language. Feedback from schools indicates, however, that this dictionary is also used by more advanced learners, even first-language speakers of Afrikaans in as high as grade 8. It is therefore not acceptable to expect foundation phase learners to consult dictionaries compiled for higher-level users.

In the planning of the foundation phase dictionary series, the publisher and lexicographers situated the dictionaries within the broader lexicographic context, realising that the approach followed in the envisaged foundation phase dictionary demands a continued process of producing follow-up dictionaries for the following levels. Although the plans for these next levels of dictionaries have not yet been developed, the publisher and lexicographers are evidently fully aware of the need to expand the present series to other phases to provide for intermediate and more advanced primary school learners. The foundation phase dictionaries were planned in such a way that they could form a basis for dictionaries compiled for the next level of dictionary users. This is part of an approach that sees dictionary use as an integral part of a process of life-long learning.

\section{Motivation for the Maskew Miller Longman foundation phase dictionaries}

MML realised the need for a dictionary directed at the specific needs and usage situation of South African foundation phase learners. This publishing house already had a monolingual English dictionary for first-language foundation phase learners, and a decision was made to embark on a series of foundation phase dictionaries for the other official South African languages, resulting in the current series of dictionaries. According to Welker (2008), the literature dealing with pedagogical lexicography primarily focuses on the position and needs of foreign-language learners and not on first-language learners (cf. Tarp and Gouws 2010). Although South Africa is a multilingual environment, where the learning of a second or additional language and therefore also the use of dictionaries directed at foreign-language learning play an important role, one should never eschew the need for dictionaries directed at learners' first languages. In order to promote the policy of multilingualism, it is important for South African learners to have a good knowledge of their mother language before moving on to the acquisition of a second language.

MML planned the compilation of a series of foundation phase dictionaries that will include a dictionary for each of the official South African languages, with the exception of English for 
which such a dictionary was already available. The dictionaries were to be compiled for mothertongue users, but provision would be made in all these dictionaries for access to English as a second language. A need was identified for multifunctional dictionaries that would respond to text reception and text production as well as the cognitive needs of the intended target users. In the early planning phase, the genuine purpose of these dictionaries was quite clearly defined, i.e. to assist foundation phase learners in solving text production, text reception and cognitive problems in their first language, and to provide English equivalents for the source language items. In the text presenting the user guidelines of the Afrikaans dictionary (Gouws, Potgieter and Burgess 2010), it is stated that:

You can use this brand-new dictionary from the first day that you go to school up to Grade 4. This dictionary will help you to:

- speak, read and write in Afrikaans as Home Language

- understand and use English as Additional Language

- learn and use Afrikaans as Additional Language.

A highlighted text box then says:

Use this dictionary for excellent results in building your vocabulary, improving spelling and reading with understanding. ${ }^{1}$

This explicitly formulated genuine purpose is complemented by the additional aim of the lexicographers, i.e. to establish and promote a dictionary culture and to familiarise the target users with dictionaries as practical instruments that can play an important role in the process of life-long learning. Consequently, the contents, different structures and functions of the dictionaries were devised to represent the contents and presentation they would later encounter in more advanced dictionaries.

The dictionaries in this series display similar structures and contents. In addition, a similar lemma selection as well as similar data types were used in all the dictionaries.

Dictionaries are compiled for specific users, but for these foundation phase dictionaries to be successful, another party comes into the equation - the educators. As is the case with their other study material, like reading books, foundation phase learners need to be instructed how to use their dictionaries. It is therefore important that educators are familiar with the specific features of these dictionaries in order to ensure the necessary successful dictionary consultation by the learners; hence, proper dictionary training or instruction for these educators is essential. When planning and eventually evaluating these dictionaries, it is important to take cognisance of the way in which the user-guidelines text enables the educators to assist the learners in the consultation process.

The following section will primarily deal with the foundation phase dictionary with Afrikaans as treated language (MML Afrikaans/English). Note, however, that the theoretical discussion also applies to the dictionaries in which other South African languages are treated.

\footnotetext{
${ }^{1}$ The same formulation is given in the other three dictionaries with specific reference to the language of those dictionaries.
} 


\section{Structures in foundation phase dictionaries}

The development of lexicographic theory has witnessed different phases with different areas of focus (cf. Gouws 2005). The first phase had the focus on the linguistic contents of dictionaries (cf. Zgusta 1971), the second phase put the emphasis on dictionary structures in the centre of research (cf. e.g. Wiegand 1983, 1984), while the third phase emphasised the role of dictionary functions (cf. Bergenholtz and Tarp 2002, and Tarp 2000). The shift in focus does not imply eschewing the focus of the preceding phase. Today it is recognised that in lexicographic research regarding general language dictionaries, the linguistic contents, structures and functions are all important. In the planning of any dictionary, the lexicographers need to pay ample attention to each one of these aspects.

Once the target user has been identified, the lexicographer needs to determine the function of the envisaged dictionary, for example, whether the function is one of text production or text reception. The next step involves the selection of the data needed to satisfy these functions. Finally, a decision has to be made regarding the presentation of the data, i.e. the lexicographic structures, so as to display and accommodate the data in such a way that the target user will have access to it and will be able to retrieve the information needed to achieve a successful dictionary consultation process. Success is achieved if answers are found to the questions that motivated the search.

In the planning of the foundation phase series, the lexicographers endeavoured to employ a variety of dictionary structures in order to distribute the required data in an optimal way and to familiarise the learners with the notion that a dictionary is a 'text compound'. One of these structures, the frame structure, will be discussed in more detail in the following subsection.

\subsection{The frame structure}

When planning the foundation phase series, the lexicographers intended that the data distribution structure should fully utilise the dictionary as a text compound. A variety of objectives with these dictionaries, e.g. their envisaged functions, compelled the data to be distributed over a number of outer texts to complement the central list, resulting in a frame structure for each one of these dictionaries. The outer texts are distributed in both the front and back matter sections of the dictionary. A few of these outer texts will be discussed.

Hausmann and Wiegand (1989:331) indicate that a dictionary has two obligatory texts, namely the central word list and a text in which the word list and its use are explained to the user. Other outer texts are seen as optional.

Every dictionary in this foundation phase series has a front matter text entitled "How to use this dictionary". The specific contents of the dictionary, not only of the central list, are discussed in this text, and example pages from the different texts are used to illustrate and explain the contribution and function of these texts. This explanation is presented in two languages, i.e. in the target language of the specific dictionary and in English. Being the first dictionary which many of the target users will encounter, it is important that they should receive appropriate guidance regarding its use. The user-guidelines text has been formulated in an easily understandable way, however, it is important that teachers familiarise themselves with this text in order to assist the dictionary users in an optimal way. 
In this user-guidelines text, it is explained that the dictionary consists of three sections, i.e. a picture dictionary with themes, the words in alphabetical order and two back matter texts presenting lists of words. This is no arbitrary selection of sections and texts to be included in these dictionaries; the contents of the front and back matter sections is determined by the ultimate goal of guiding the target users in the process of becoming familiar with dictionaries as sources of reference.

\subsubsection{The picture dictionary with themes}

Because this dictionary makes provision for learners from their very first day at school, a picture section has been included which may be used during the pre-literate stage. This section in the front matter consists of a pictorial representation of a number of themes frequently used in the foundation phase, e.g. My Body, Clothing, My Family, Our Home, Places and People, Things that We Do, Transport, etc. These themes were selected for inclusion after consultation with experts within the field of foundation phase education. Each theme is presented on either a double or a single page, with the topic of the theme clearly indicated in the top left-hand corner. The centre of the page contains a picture frame in which a number of small pictures depict various aspects of the theme. Next to the picture frame are small pictures extracted from the main picture along with the relevant word for the concept illustrated by the small picture and its English translation equivalent. This can be seen in Figure 1.

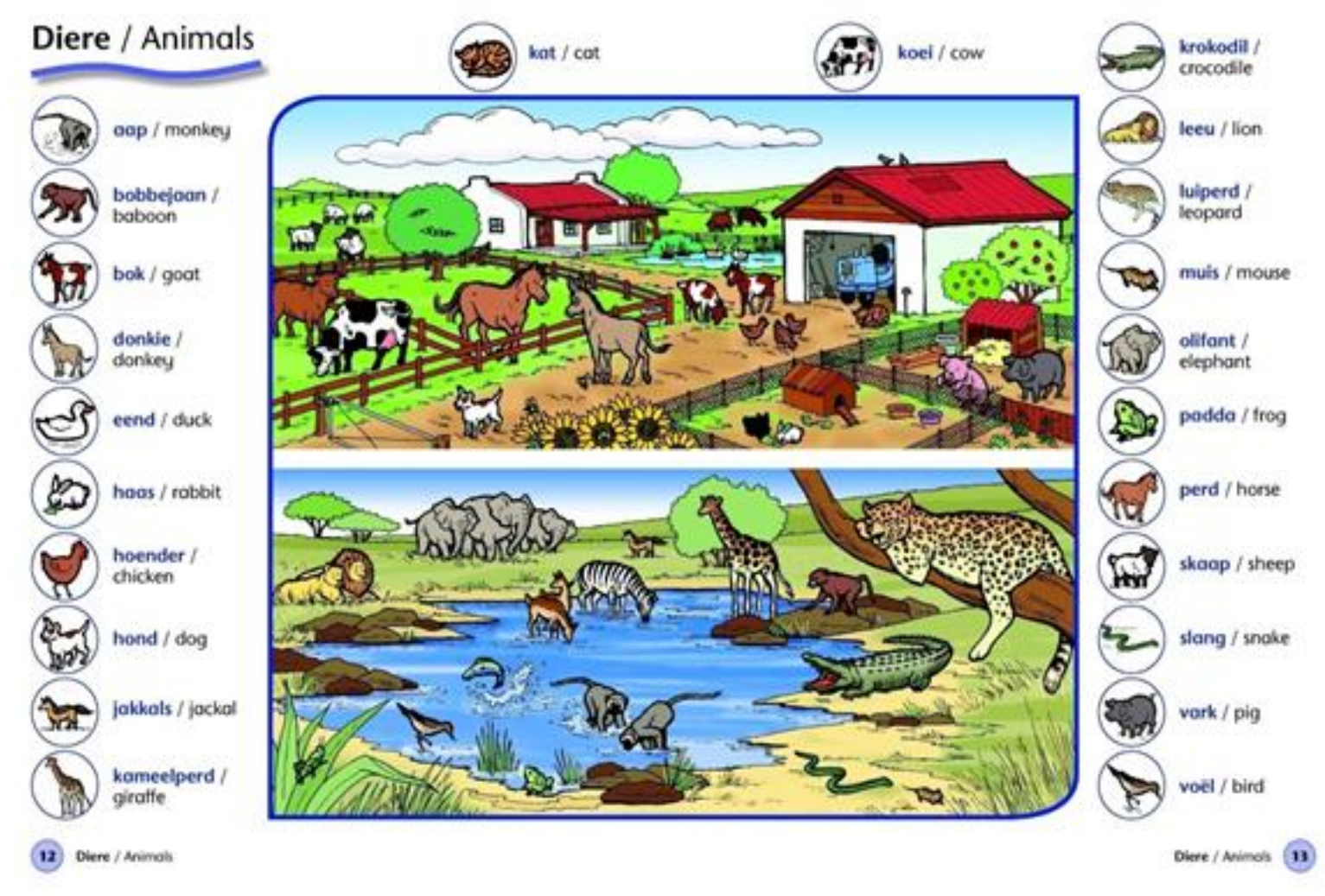

Figure 1. Pictorial representation of the Animals theme in MML Afrikaans/English 
In a traditional thematically ordered dictionary, the user moves from a given concept to a word for that meaning. This is the typical approach in an onomasiological dictionary (cf. Reichmann 1990). A large number of the potential target users of the foundation phase dictionaries are not yet able to read. They can, however, relate to the pictures presented in the thematic component. The aim of this section of the dictionary is to guide users from a picture to a word. Seeing the picture and word together puts them in a position to make the necessary link between the concept, as expressed by means of the picture, and the relevant word. At this early stage, the English word is also given to establish the bilingual dimension of these predominantly monolingual dictionaries.

\subsubsection{The central list: Words in alphabetical order}

The main component of each one of the dictionaries in the MML series is an alphabetical central list. The words included in this list have not been selected in an arbitrary way, but in terms of the vocabulary needs of the intended target users.

A distinction is made between single and complex articles, with the single article being the default form. The items, i.e. the entries from which the dictionary user can retrieve some information regarding the subject matter of the specific dictionary, include the past tense (verbal lemmas), plural (noun lemmas), an English equivalent of the word represented by the lemma sign, a paraphrase of meaning, an example sentence, an English translation of the example sentence and a repetition of the small picture appearing in the thematic picture dictionary along with a page number that refers the user to the relevant page in the thematic picture dictionary. Page numbers given in bold indicate that the word is included on the theme page; when a page number is not given in bold, it indicates that the word forms part of the theme, but has not been included on the theme page. Where a word given as a lemma sign does not occur in the thematic picture dictionary, no page number accompanies the picture. Complex articles also have additional items, e.g. items giving the opposite form of a given word or notes that provide more information about a word and how it is used. Figure 2 is an example of a section of an alphabetical central list in MML Afrikaans/English. 


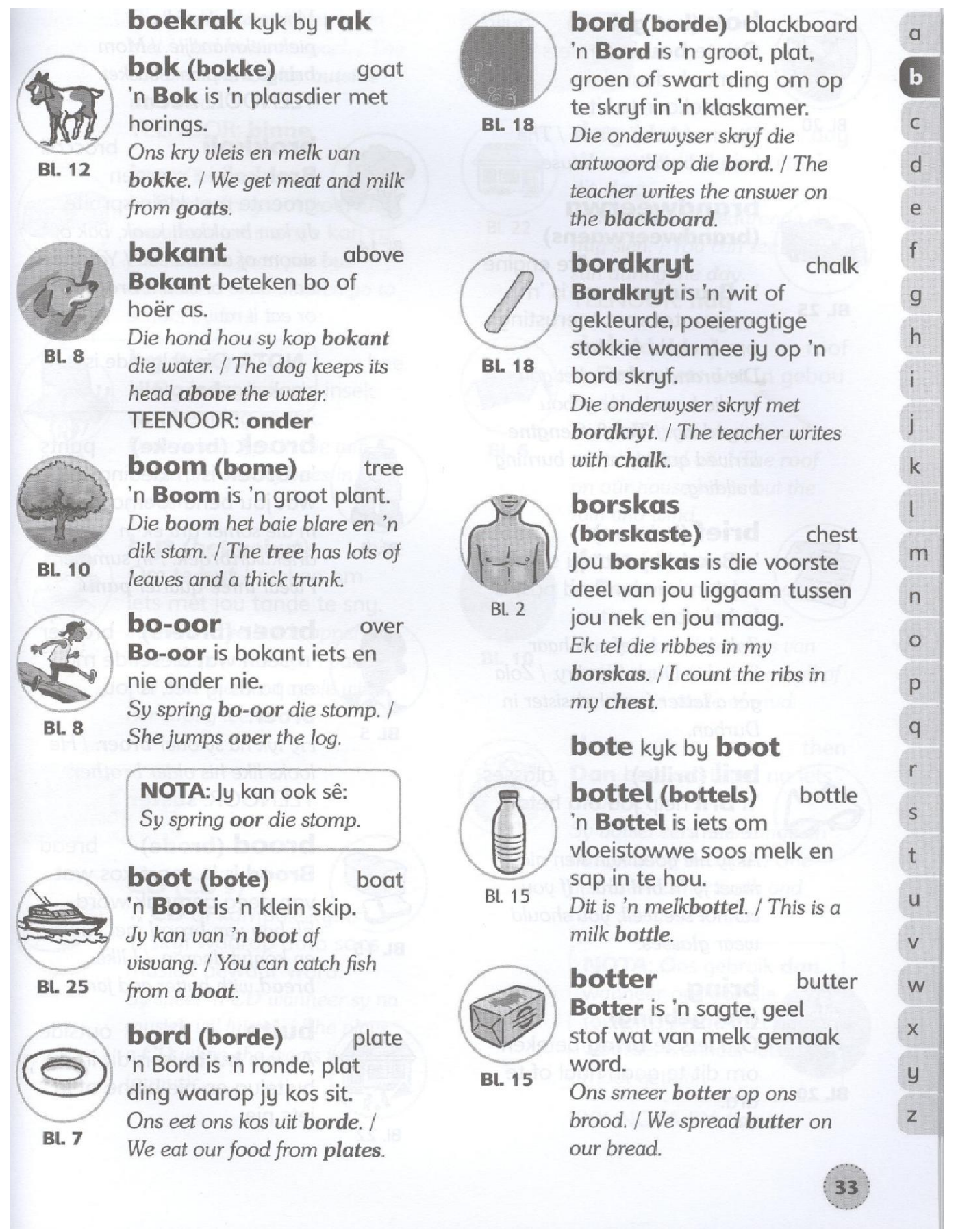

Figure 2. A section of the alphabetical central list in MML Afrikaans/English

The positioning of the small pictures in the word list is another feature of these dictionaries that illustrates a user-directed approach. The pictures are phased out to the left of the article and precede the lemma that functions as the primary guiding element of a specific article. The position is typically macro-structural, which implies that the pictures can also be seen as part of a two-headed lemma consisting of a picture and a word as a lemma sign. This position implies that the pictures can also be employed as guiding elements by the users. For foundation phase learners who are not yet that familiar with reading, the co-occurrence of a picture in the guidingelement position can be a major support in recognising the desired word. The fact that the same pictures appear in both the thematic dictionary and the central list adds to the functionality of 
these pictures. They become anchoring elements that link the article in the central list to the thematic dictionary in the outer text.

The motivation for some of the items in the default dictionary articles is as follows: the young users of these dictionaries need to use the dictionary for text reception purposes to acquire the meaning of a given word which they have encountered in their syllabus. A brief paraphrase of meaning in the mother tongue of the primary target users assists these users in retrieving the meaning of the word. At a slightly later stage during their first school year, they also have to make sentences with a word and therefore need to consult the dictionary for text production purposes. During the first year of the foundation phase, South African learners start with English as their first additional language, with the result that each article in these dictionaries contains an English translation equivalent. When the learners have to start making sentences with English words, the item giving an English example sentence can help to satisfy their text production needs.

\subsubsection{The list of words}

Each dictionary in this foundation phase series has two outer texts in the back matter section. These texts appear as alphabetical word lists in Afrikaans-English and English-Afrikaans. The Afrikaans list is actually a lemma list with the English translation equivalents and a reference to the pages in either the central list or in both the thematic picture dictionary and the central list. The English list is an equivalent index complemented by the relevant Afrikaans lemma, and also contains a reference to the pages in either the central list or the thematic picture dictionary and the central list (see Figure 3). 


\section{List of words: English - Afrikaans}

\begin{tabular}{|c|c|c|}
\hline $\begin{array}{l}\text { Aa } \\
\text { above bokant } 8 ; 33 \\
\text { across oor } 64 \\
\text { add optel } 65 \\
\text { address adres } 27 \\
\text { aeroplane vliegtuig } 25 ; 87 \\
\text { after na } 60 \\
\text { again weer } 91 \\
\text { against teen } 80 \\
\text { age ouderdom } 65 \\
\text { air lug } 10 ; 56 \\
\text { airport lughawe } 56 \\
\text { alphabet alfabet } 28 \\
\text { ambulance } \\
\text { ambulans } 25 ; 28 \\
\text { angry kwaad } 53 \\
\text { animal dier } 36 \\
\text { ankle enkel } 2 ; 39 \\
\text { answer antwoord } 28 \\
\text { apple appel } 14 ; 28 \\
\text { arm arm } 2 ; 28 \\
\text { art kuns } 52 \\
\text { ask vra } 88 \\
\text { aunt tannie } 5 ; 80 \\
\text { autumn herfs } 10 ; 45 \\
\text { awake wakker } 90 \\
\text { away weg } 91 \\
\text { Bb } \\
\text { baboon bobbejaan } 12 ; 32 \\
\text { baby baba } 29 \\
\text { back agter } 8 ; 22 ; 28 \\
\text { bad sleg } 75 \\
\text { bake bak } 29 \\
\text { baker bakker } 29 \\
\text { bakery bakkery } 16 ; 30 \\
\text { ball bal } 24 ; 30 \\
\text { banana piesang } 14 ; 67 \\
\text { and }\end{array}$ & $\begin{array}{l}\text { bank bank } 16 ; 30 \\
\text { bark blaf } 32 \\
\text { bath bad } 6 ; 29 \\
\text { bathroom badkamer } 29 \\
\text { beautiful pragtig } 10-11 \\
\text { because omdat } 63 \\
\text { bed bed } 6 ; 30 \\
\text { bedroom slaapkamer } 75 \\
\text { bee by } 34 \\
\text { before voor } 88 \\
\text { begin begin } 30 \\
\text { beginning begin } 30 \\
\text { behind agter } 8 ; 22 ; 28 \\
\text { bell klok } 18 ; 50 \\
\text { below onder } 9 ; 63 \\
\text { bicycle fiets } 25 ; 40 \\
\text { big groot } 22 ; 43 \\
\text { bird voël } 13 ; 87 \\
\text { birthday verjaardag } 85 \\
\text { bite byt } 34 \\
\text { black swart } 1 \\
\text { blackboard bord, } \\
\text { swartbord } 18 ; 33 ; 79 \\
\text { blanket kombers } 51 \\
\text { blouse bloes } 32 \\
\text { blue blou } 1 \\
\text { boat boot } 25 ; 33 \\
\text { body liggaam } 2-3 ; 56 \\
\text { book boek } 18 ; 32 \\
\text { bottle bottel } 33 \\
\text { bottom (at the) onderaan } \\
63 \\
\text { boy seun } 73 \\
\text { branch tak } 11 ; 79 \\
\text { bread brood } 15 ; 34 \\
\text { breakfast ontbyt } 63 \\
\text { brick baksteen } 30 \\
\text { bring bring } 34 \\
\text { broccoli brokkoli } 34 \\
\text { bo }\end{array}$ & $\begin{array}{l}\text { broom besem } 31 \\
\text { brother broer } 5 ; 34 \\
\text { brown bruin } 1 \\
\text { bug gogga } 42 \\
\text { build bou } 34 \\
\text { building gebou } 40 \\
\text { bury begrawe } 31 \\
\text { bus bus } 25 ; 34 \\
\text { butcher slagter } 17 ; 75 \\
\text { butchery slagtery } 75 \\
\text { butter botter } 15 ; 33 \\
\text { buy koop } 51 \\
\text { CC } \\
\text { cabbage kool } 51 \\
\text { cake koek } 50 \\
\text { calculator sakrekenaar } \\
26 ; 72 \\
\text { calendar almanak } 28 \\
\text { call roep } 70 \\
\text { camera kamera } 26 ; 48 \\
\text { car motor } 25 ; 60 \\
\text { carpet mat } 58 \\
\text { carrot wortel } 14 ; 92 \\
\text { carry dra } 20 ; 38 \\
\text { cashier kassier } 16 ; 48 \\
\text { cat kat } 12 ; 48 \\
\text { catch vang } 21 ; 84 \\
\text { cattle bees } 30 \\
\text { cauliflower blomkool } 32 \\
\text { CD CD } 26 ; 35 \\
\text { cellphone selfoon } 26 ; 72 \\
\text { cent sent } 72 \\
\text { chair stoel } 6 ; 19 ; 78 \\
\text { chalk bordkryt } 18 ; 33 \\
\text { cheek wang } 3 ; 90 \\
\text { cheese kaas } 15 ; 47 \\
\text { chest borskas } 33 \\
\text { chicken hoender } 12 ; \\
15 ; 45 \\
\text { ch }\end{array}$ \\
\hline
\end{tabular}

Figure 3. A section of the word lists for English/Afrikaans in MML Afrikaans/English

The Afrikaans-English list provides the knowledgeable user with quick access to the English translation equivalents of a given word as well as linking the occurrence of a given word in the picture dictionary with the central word list. The English list enhances the poly-accessible nature of the dictionary: a user who encounters an unknown English word can consult the English-Afrikaans list to find the Afrikaans equivalent as well as the relevant page number(s). The user can then proceed to the article in the central list where a paraphrase of meaning of the English word can be found in his/her mother tongue. The secondary objective of these 
dictionaries, i.e. to assist users in their study of English as an additional language, is partly achieved by this inclusion of English equivalents and example sentences, and the two alphabetical back matter texts.

\subsubsection{Other outer texts}

Two other outer texts should also be mentioned in this discussion, namely the table of contents and the text "Your personal dictionary".

The table of contents includes a reference to all the different texts in the dictionary. The reference to the section "Picture dictionary with themes" has several subdivisions listing each individual theme. In this listing, the topic of the theme is given and is preceded by a small picture representing that theme. This enables the rapid identification of the theme by a user who still only has limited reading skills. An important contribution of the table of contents is the fact that it makes users aware of the variety of texts included in these dictionaries. Therefore, from an early encounter with dictionaries, users view them not only as a source with a single text, i.e. the central list, but they experience the dictionary as a text compound with different texts that accommodate a variety of data types from which the necessary information can be retrieved.

The front matter text "Your personal dictionary" occupies only a single page, but gives a very specific dimension to these dictionaries. By means of this text, the user is inspired to utilise their own lexicographic creativity and gets the opportunity to add whatever s/he regards to be of significance to the dictionary. This text can be put to good use by teachers to help users with the development of their dictionary-utilisation skills. Yet again, the important role of the teachers and the dictionary's potential application in the classroom should not be underestimated.

\section{Challenges and considerations}

Most of the challenges discussed in this section revolve around the integration of the treatment of the lemmas and their pictorial illustrations in the Sotho languages with examples mostly taken from MML. Some relate to the Sotho languages and the African languages in general, or are problematic in any language. The underlying deficiency relates to pictures that do not contribute to better understanding of the lemma. In the Sotho languages, grammatical divergence and mismatch in terms of equivalence relations are also major problematic factors.

A general and universal challenge for any language is the difficulty of illustrating many concepts by means of a single picture. Consider the concept of 'clean(liness)' as a typical example. The picture given in MML Sepedi/English in Figure 4 attempts to contrast clean clothes with dirty clothes, and the arrow is used as a device to focus the attention on the relevant subpart of the picture.

\section{hlwekile / clean}

Figure 4. Pictorial illustration of hlwekile in MML Sepedi/English 
In contrast, the Oxford First Bilingual Dictionary (Hiles and Mokhoane 2007:12) attempts to illustrate "clean" by means of a shiny pair of shoes (in Figure 5):

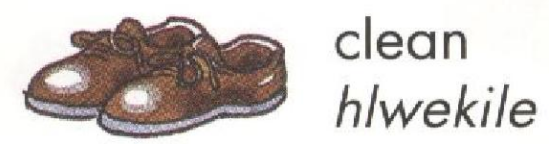

Figure 5. Pictorial representation of "clean" in the Oxford First Bilingual Dictionary

This is even less effective than the representation of this concept in MML Sepedi/English because the shining spots go unnoticed due to the relatively small size of the picture.

The difficulty in visualising this concept becomes clear when a number of Google images for "clean" were studied. It is evident that the concept is approached from many angles, such as showing people washing objects or their bodies, images of cleaning equipment (e.g. a broom), detergents, etc. In each of these cases, if the message is not accompanied by text, the message could be interpreted as something else. For example, with regard to the images in Figure $6^{2}$, the first image (top left) could simply be portraying a boy washing himself; the second image (top right) could be a representation of children on a cleaning mission in the street; the third image (bottom left) could be a portrayal of a child playing in the bath; and the fourth image could merely illustrate a girl throwing paper in a rubbish bin.

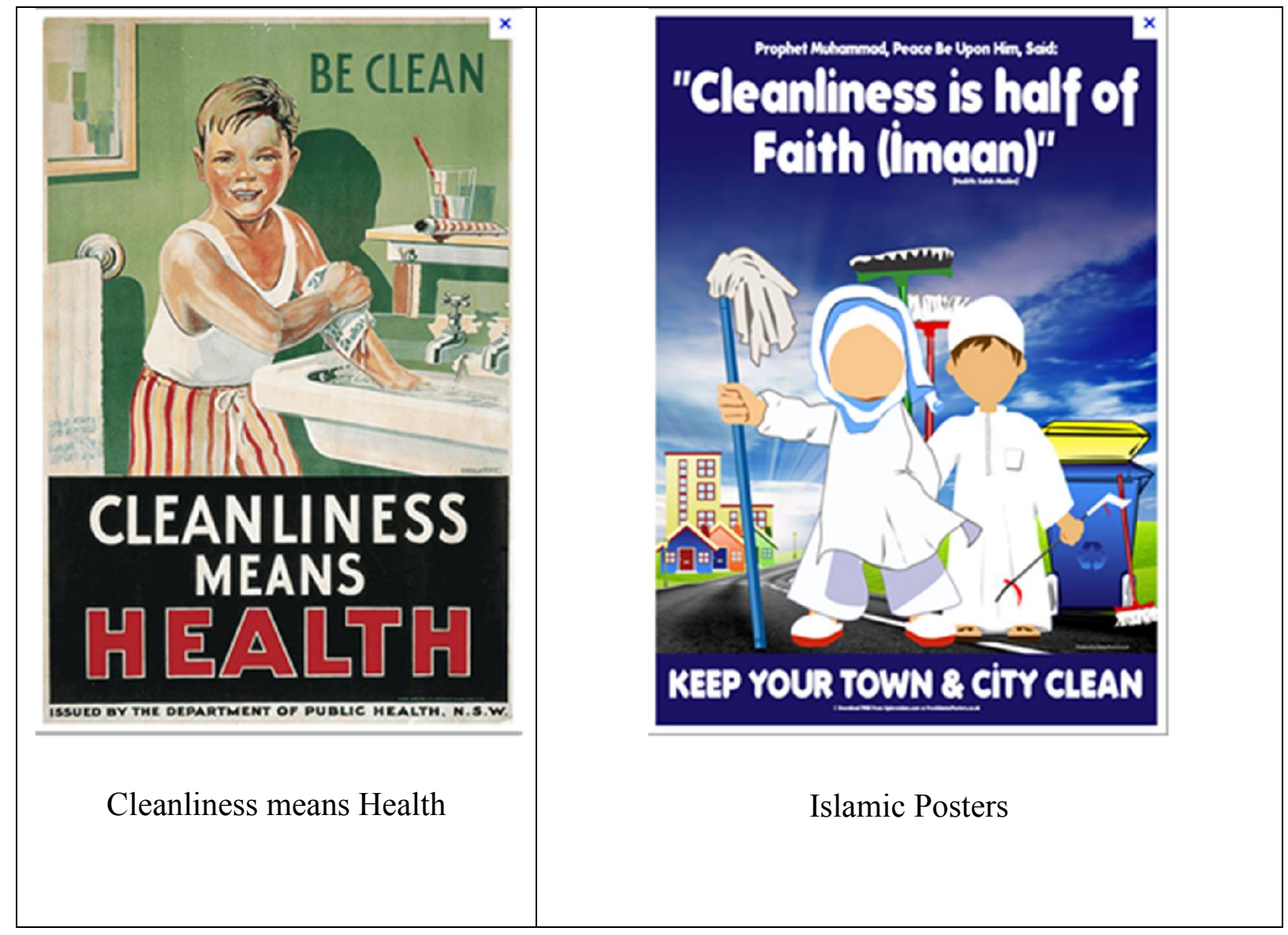

\footnotetext{
${ }^{2}$ See the reference list at the end of this article for the URLs for each picture.
} 


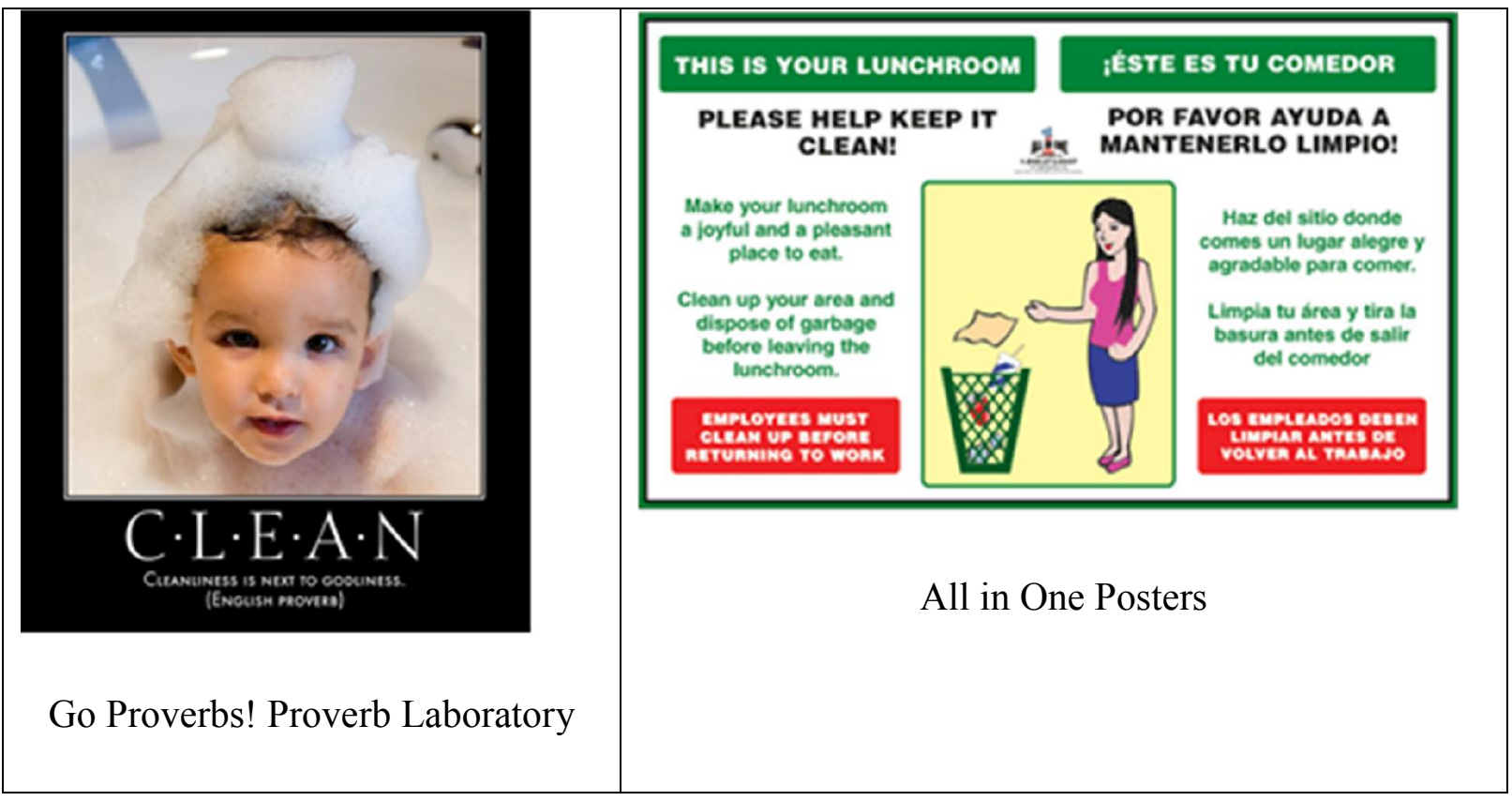

Figure 6. A series of illustrations for "clean"

It is thus important to note the crucial role that the inserted texts play in each of the pictures in order to focus on the aspects of cleanliness.

In a similar vein, consider the pictures in Figure 7 accompanying the lemmas "happy" and "unhappy" in MML isiXhosa/English.

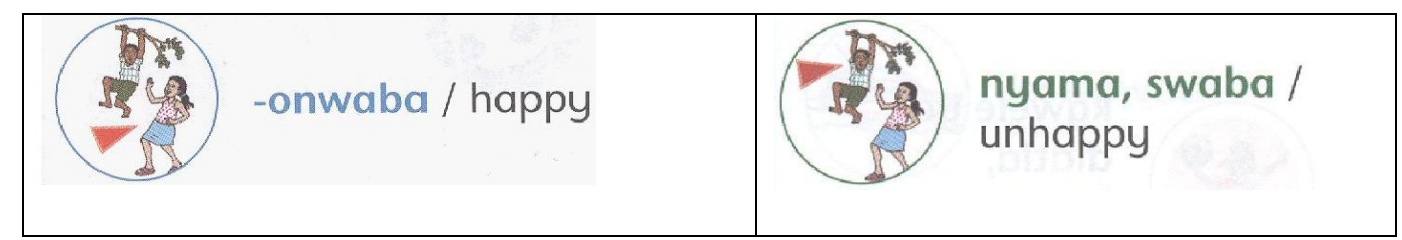

Figure 7. Pictorial illustration of "happy" and "unhappy” in MML IsiXhosa/English

Both of these pictures could simply be interpreted as two people enjoying themselves in different ways, one by dancing and the other by playing in a tree. The intention of the use of the arrow in both pictures is not clear and may be confusing as it does not add value to the article. 
Turning more specifically to Sepedi, consider the picture for "ask" in MML Sepedi/English (Figure 8):

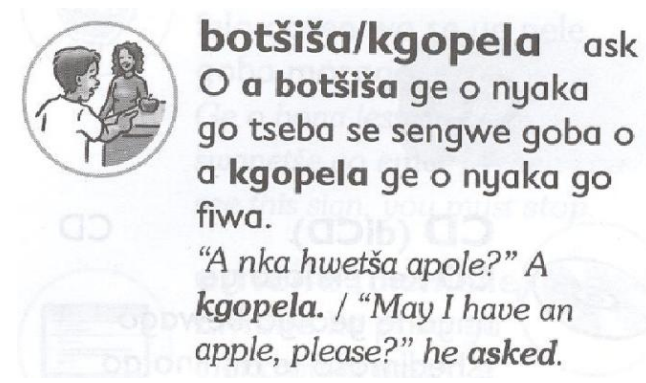

Figure 8. Pictorial illustration of "ask" in MML Sepedi/English

Firstly, this picture could be interpreted simply as two children talking to each other. In the treatment of the lemmas, both meanings, i.e. botšiša ('ask a question') and kgopela ('ask for something'), are clearly indicated. Since the picture does not add value to the article and does not link to a thematic page, it could be left out. It is not necessary for all lemmas to be illustrated with pictures. However, in cases where the lemma is linked to a thematic category, illustration with pictures is essential. A departure from the thematic section of the dictionary to the alphabetical section, where treatment of the lemmas is offered, has many virtues. As explained in section 4.1.1, the user becomes more skilled at utilising the different sections of the dictionary, and the thematic part constitutes a major component thereof.

There is no doubt that pictures can be of great value in a dictionary. Al-Kasimi (1977) states that pictures should be used in cases where it is difficult to illustrate lexicographic relations such as spatial relations, e.g. "span" in the context of an aeroplane's wingspan, the length of a bridge or a hand, etc. In principle, pictures are not suited to illustrate verbal relations, as in the case of botšiša and kgopela in Figure 8. Here, a written definition would have sufficed. Just as a written definition can be insufficient, so can a pictorial illustration also not contribute to a better understanding of the meaning of a word, with the result that such pictures become redundant.

It is a concern if pictures are not planned by lexicographers. Graphic designers do not necessarily know what the lexicographic function of a picture is. Lexicographers therefore should have a say in the design of a picture and where it should fit in as pictures are a type of lexicographic device and should not solely be a publishing initiative. The lexicographer should be consulted on whether or not a picture should be presented, how the picture should look and where it should be placed.

The decontextualisation of pictures can also be problematic. In the case of -tala/-tšofetše ('old') in Figure 9, a picture of a mother pushing her child in a pram is given with the focus arrow pointing to the mother.

-tala, tšofetše /

old

Figure 9. Pictorial illustration of "old" in MML Sepedi/English 
Taken at face value, it could be argued that a picture of an aged person would be more appropriate here. However, looking at the picture in Figure 10, which portrays the theme of Opposites (page 22/23 in all four of the dictionaries), the picture as a whole makes more sense when a number of activities involving young people versus adults are depicted.

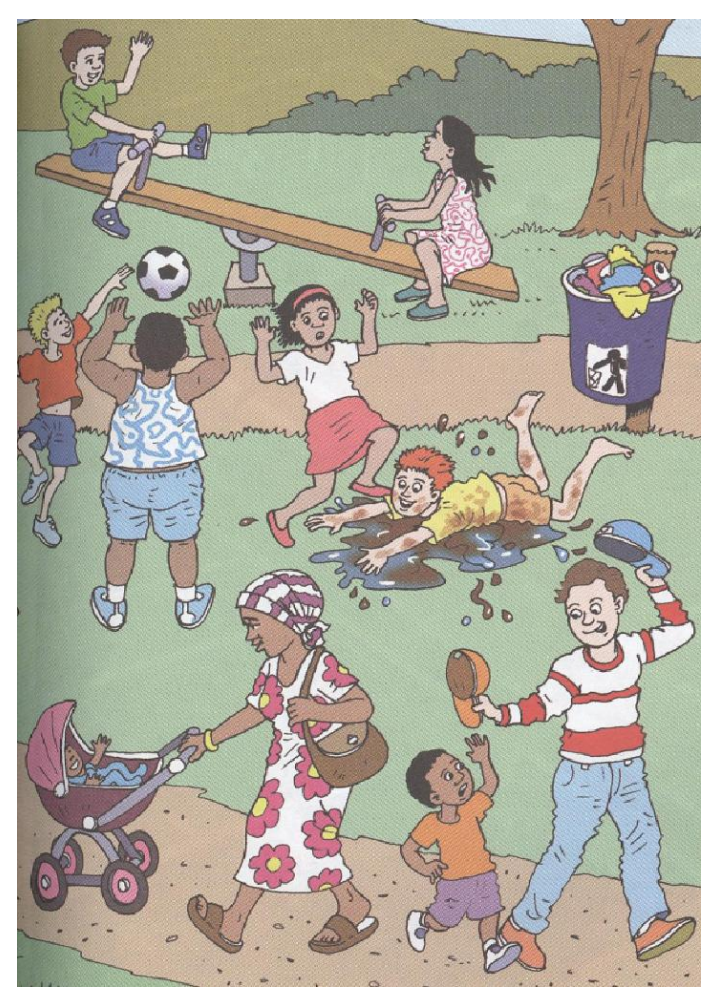

Figure 10. Pictorial representation of the theme of Opposites in MML

It is therefore necessary, and of great value to the user, to follow the cross-reference to the alphabetical section, especially when the intended information conveyed by the picture is not clear to the user.

The same holds true for -golo ('big') which, in the picture-guiding element to the side of the main picture, does not successfully illustrate 'big', yet in the main picture the tree is indeed relatively large in comparison with other objects in the picture. There is also a mismatch in terms of the pictorial illustration between this theme page for Opposites and the lemmas for -golo given in the alphabetical section, where -golo ('big') and -golo ('large'), are depicted on page 38 by an elephant instead of a tree.

Conveying the right information regarding adjectives such as -golo has another problematic dimension in African languages, namely different forms for each of the noun classes. When "big" is expressed in relation to a noun in, for example, class 7, e.g. sehlare ('tree'), the adjective is segolo, but mogolo for classes 1 and 3, bagolo for class 2, megolo for class 4, legolo for class 5, magolo for class 6 , etc. The lexicographer thus has to find a way to inform the user of the full paradigm in order for the latter not to produce the wrong form for a specific noun. The same holds true for paradigms such as "he/she" (o/a/ba/le/a/se/di/bo), "this" (yo/ba/wo/yel le/a/tše/bjo), etc. (cf. Prinsloo and Gouws 2006). The lexicographer should not regard it as sufficient to give limited information simply because it is a foundation phase dictionary. 
Handling these kinds of paradigms, which Prinsloo and Gouws (2006) call "grammatical diversion", is indeed a challenge to the lexicographer. The main problem with the presentation of full paradigms is that the inclusion of a number of the members of such a paradigm is not justified on the basis of frequency. So, for example, users should know that tswalela means "to close a gate/door", but khurumela means "to close a lid". The problem is that tswalela, with a frequency count of 385 in the Pretoria Sepedi Corpus (PSC), is 15 times more frequently used than khurumela, which has a frequency count of 25 . It is accepted that precious dictionary space should not be sacrificed for merely completing a paradigm which may come at the expense of other worthy candidates for inclusion. However, in the case of khurumela, it should not be omitted simply because inclusion might not be justified on the basis of frequency. The same holds true for "rubbish" which can be translated as ditšhila ('dirt') or matlakala ('leaves'), but the latter does not necessarily mean 'dirt', e.g. matlakala a sehlare ('leaves of the tree').

Another problematic aspect related to paradigms, frequency of use and complexity of terminology is the treatment of kinship terminology in a foundation phase dictionary (cf. Prinsloo and Van Wyk (1992) for a detailed discussion). For example, the English term "uncle" relates to a complex set of equivalents in Sepedi, e.g. malome ('mother's brother'), ramogolo ('father's older brother') and rangwane ('father's younger brother'); similarly, the English term "aunt" also has a complex set of equivalents in Sepedi, such as rakgadi ('father's younger sister'), mmane ('mother's younger sister'), mmamogolo ('mother's eldest sister'), etc. Even a single kinship term could have complex references, for example, kgaetšedi ('younger sister of a brother' or 'younger brother of a sister') or rakgadi ('father's younger sister' or 'this woman's husband or a related uncle'). The same is true when it comes to the Nguni languages, for instance, the English terms "uncle" and "aunt" relate to a set of equivalents in isiXhosa, e.g. malume ('mother's brother'), tat'omkhulu ('father's older brother'), tat'omncinci ('father's younger brother'), and anti ('uncle's wife'), makazi ('mother's sister') and dadobawo ('father's sister'), respectively.

The challenge for the lexicographer is to maintain a sound balance between the selection of the terms, the extent of the treatment, the detail of the distinction and the target user's skills and existing knowledge. On the theme page entitled Usapho lwam in MML IsiXhosa/English and that of Lapa lešo in MML Sepedi/English (both on the theme of My Family), the pictures go some way in respect of gender and age, e.g. rakgolo ('grandfather') is an old male while intombi/morwedi ('daughter') is a young female. They, however, do not contribute to kinship distinction. Having a picture of a bride for intombi/morwedi ('daughter') could even be misleading because the learner could conclude that intombi/morwedi is a bride. Special attention should also be given to borders of uniformity, e.g. family versus relatives. Guidance should be clear to an Afrikaans-speaking learner of English (or vice versa) in terms of the relation of the Afrikaans terms gesin ('family') versus familie ('relatives').

Problems with certain concepts and concept illustration could be improved or rectified, e.g. with regard to the depiction of "left" and "right" in a picture (see Figure 11). 


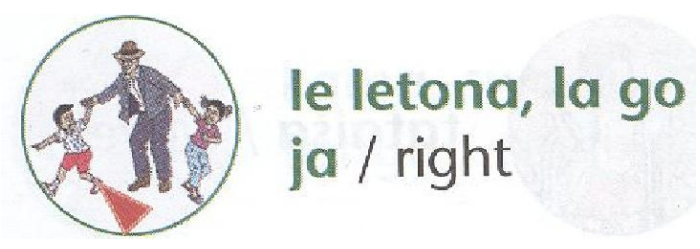

Figure 11. Pictorial illustration of "right" in MML Sepedi/English

In this illustration, the focus arrow points to the child to the right of the father, but the child is on the left-hand side of the picture. A solution could be to portray the people from behind, where the right-hand side of the picture would coincide with the father's right-hand side. Ideally, illustrations reflecting opposites or contrast should be grouped together, e.g. doing the same for "left" in this case.

In the case of go se na le selo ('empty'; MML Sepedi/English), an empty glass is pictured (Figure 12).

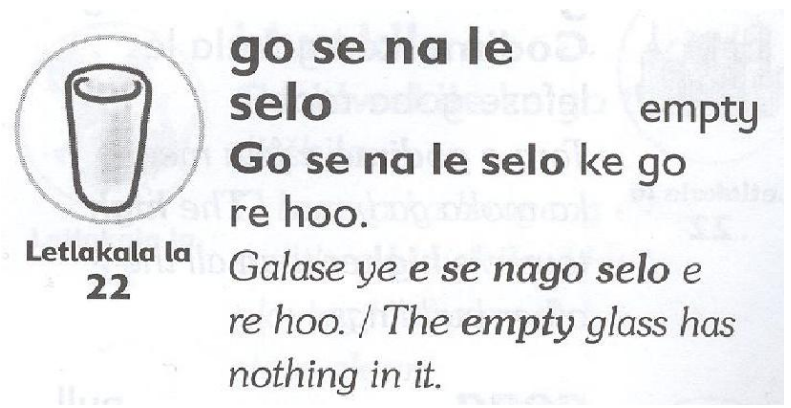

Figure 12. Pictorial illustration of "empty" in MML Sepedi/English

Here, a full glass and an empty glass in the same picture, with the arrow pointing to the empty glass, would have been a better choice. There is also a mismatch between this picture and the one given on the thematic page 22 depicting "empty".

The issue of the inclusion of loan words versus indigenous words is a universal one. For the African languages, the challenge here is no different from other dictionaries. While it is imperative to include loan words relating to the high-tech world in which the target users find themselves, a good balance should be struck between the inclusion of loan words and indigenous words.

\section{Summary and conclusion}

When planning a new dictionary, lexicographers should have the user perspective as point of departure. The design and production of user-friendly dictionaries which are suitable for the level and needs of their prospective users, is non-negotiable. Furthermore, lexicographers should negotiate the position of the envisaged dictionary within a broader family of dictionaries, even if the other members of the family have not yet been compiled. Publishers and lexicographers should be well aware that the approach followed in the envisaged foundation phase dictionary demands a continued process of producing follow-up dictionaries for the subsequent levels. The foundation phase dictionaries should form a basis for those compiled for the next level of dictionary users. This forms part of an approach that sees dictionary use as 
an integral part of a process of life-long learning, thereby establishing and promoting a dictionary culture. The target users should be familiarised with dictionaries as practical instruments that can play an important role in a process of life-long learning.

During the design process of foundation phase dictionaries, cognisance should be taken of the fact that foundation phase learners are in need of lexicographic assistance, especially given the fact that they only have limited reading skills at this stage.

The MML foundation phase dictionaries were compiled for mother-tongue users, but provision was made for access to English as a second language. These dictionaries are identified as multifunctional that would respond to text reception and text production as well as the cognitive needs of the intended target users. Furthermore, the genuine purpose of these dictionaries was clearly defined, i.e. to assist foundation phase learners in solving text production, text reception and cognitive problems in their first language, and to provide English equivalents for the source language items. It is our suggestion, however, that this purpose could best be achieved by presenting the data in three sections, namely a picture dictionary with themes, the words in alphabetical order and two back-matter texts presenting lists of words.

Naturally, every dictionary and dictionary design has limitations and challenges. Most of the challenges discussed in this article revolve around the integration of the treatment of the lemmas and their pictorial illustrations, and should be addressed in future revision of the dictionaries.

\section{Acknowledgements}

This research is (a) conducted within the SeLA project (Scientific e-Lexicography for Africa), supported by a grant from the German Ministry for Education and Research, administered by the DAAD (R.H. Gouws and D.J. Prinsloo); and (b) supported in part by the National Research Foundation of South Africa (grant-specific unique reference numbers (UID) 85434 R.H. Gouws and 85763 D.J. Prinsloo). The Grantholders acknowledge that the opinions, findings and conclusions or recommendations expressed in any publication generated by the NRF-supported research are those of the authors, and that the NRF accepts no liability whatsoever in this regard.

\section{References}

\section{Dictionaries}

Dlali, M. 2010. Longman isichazi-magama-siseko. IsiXhosa/English. Cape Town: Maskew Miller Longman.

Gouws, R., L. Potgieter and S. Burgess (eds.) 2010. Longman grondslagfasewoordeboek Afrikaans/Engels. Cape Town: Maskew Miller Longman.

Gouws, R.H., M. Stark and L. Gouws. 2004. Nuwe woordeboek sonder grense. Cape Town: Maskew Miller Longman.

Hiles, L. and M. Mokhoane (eds.) 2007. Oxford first bilingual dictionary Sesotho sa Leboa/English. Cape Town: Oxford University Press Southern Africa 
Mabule, M. 2010. Longman pukuntšu ya sehlopafase: Sepedi/English. Cape Town: Maskew Miller Longman.

Ramagoshi, R. 2010. Longman thanodi ya kgatho ya motheo: Setswana/English. Cape Town: Maskew Miller Longman.

Zulu, N.S. 2010. Longman isichazamazwi sezinga eliyisisekelo: IsiZulu/English. Cape Town: Maskew Miller Longman.

\section{Other sources}

Al-Kasimi, A.M. 1977. Linguistics and bilingual dictionaries. Leiden: E.J. Brill.

Bergenholtz, H. and S. Tarp. 2002. Die moderne lexikographische Funktionslehre. Diskussionsbeitrag $\mathrm{zu}$ neuen und alten Paradigmen, die Wörterbücher als Gebrauchsgegenstände verstehen. Lexicographica 18(2002): 253-263.

De Schryver, G-M and D.J. Prinsloo. 2011. Do dictionaries define on the level of their target users? A case study for three Dutch dictionaries. International Journal of Lexicography 24(1): $5-28$.

Gouws, R.H. 2001. Lexicographic training: Approaches and topics. In J.D. Emejelu (ed.) Elements de lexicographie Gabonaise. Tome I. New York: Jack Hillman Publishers. pp. 58-94.

Gouws, R.H. 2005. Meilensteine auf dem historischen Weg der Metalexikographie. Lexicographica 21: 158-178.

Gouws, R.H. 2006. Leerdergedrewe leksikografie. Tydskrif vir Taalonderrig 40(1): 72-84.

Gouws, R.H. 2007. Op pad na 'n nuwe woordeboektipologie. Southern African Linguistics and Applied Language Studies 25(3): 319-331.

Hausmann, F.J. 1989. Die gesellschaftlichen Aufgaben der Lexikographie in Geschichte und Gegenwart. In F.J. Hausmann, O. Reichmann, H.E. Wiegand and L. Zgusta (eds.) Wörterbücher, dictionaries, dictionnaires. An international encyclopedia of lexicography. First volume. Berlin: De Gruyter. pp. 1-19.

Hausmann, F.J. and H.E. Wiegand. 1989. Component parts and structures of general monolingual dictionaries: A survey. In F.J. Hausmann, O. Reichmann, H.E. Wiegand and L. Zgusta (eds.) 1989-1991. Wörterbücher, dictionaries, dictionnaires. An international encyclopedia of lexicography. First volume. Berlin: De Gruyter. pp. 328-360.

Hausmann, F.J., O. Reichmann, H.E. Wiegand and L. Zgusta (eds.) 1989-1991. Wörterbücher, dictionaries, dictionnaires. An international encyclopedia of lexicography. First volume. Berlin: De Gruyter.

Prinsloo, D.J. and R.H. Gouws. 2006. Lexicographic presentation of grammatical divergence in Sesotho sa Leboa. South African Journal of African Languages 16(4): 184-197. 
Prinsloo, D.J. and J.J. van Wyk. 1992. Verwantskapsterminologie van die Noord-Sotho. South African Journal of Ethnology 15(2): 43-58.

PSC. Pretoria Sepedi Corpus. University of Pretoria.

Reichmann, O. 1990. Das onomasiologische Wörterbuch: Ein Überblick. In F.J. Hausmann, O. Reichmann, H.E. Wiegand and L. Zgusta (eds.) 1989-1991. Wörterbücher, dictionaries, dictionnaires. An international encyclopedia of lexicography. First volume. Berlin: De Gruyter. pp. 1057-1067.

Tarp, S. 2000. Theoretical challenges to LSP lexicography. Lexikos 10: 189-208.

Tarp, S. and R.H. Gouws. 2010. Skoolwoordeboeke vir huistaalleerders van Afrikaans. Lexikos 20: 466-494.

Tarp, S. and R.H. Gouws. 2012. School dictionaries for first language learners. Lexikos 22: 333351.

Tarp, S. and L.R. Miyares. 2013. Cuban school dictionaries: A shared experience. Lexikos 23: 414-425.

Welker, H.A. 2008. Panorama geral da lexicografia pedagógica. Brasilia: Thesaurus Editora.

Wiegand, H.E. 1983. Ansätze zu einer allgemeinen Theorie der Lexikographie. In J. Schildt and D. Vieweger (eds.) Die Lexikographie von heute und das Wörterbuch von morgen. Berlin: Akademie. pp. 92-127.

Wiegand, H.E. 1984. On the structure and contents of a general theory of lexicography. In R.R.K. Hartmann (ed.) LEXeter '83 Proceedings. Papers from the International Conference on Lexicography at Exeter, 9-12 September 1983. Tübingen: Max Niemeyer. pp. 13-30.

Wiegand, H.E. 1998. Wörterbuchforschung. Berlin: De Gruyter.

Zgusta, L. 1971. Manual of lexicography. The Hague: Mouton.

\section{Web pages}

All in One Posters. 2014. Available online: http://www.allinoneposters.com/s.nl/it.A/id. 1019/.f (Accessed 22 February 2014).

Go Proverbs! Proverb Laboratory. 2013. Available online: http:/goproverbs.blogspot.com/ 2013/03/poster-cleanliness.html (Accessed 22 February 2014).

Cleanliness means Health. 2014. Available online: http://www.ilmoamal.org/bms/q unit slide.php?unit $\mathrm{id}=462 \&$ slide order=1\&login required=no (Accessed 22 February 2014).

Islamic Posters. 2014. Available online: http://www.islamicposters.co.uk/posters/Aadhaab/ Camel Hump Hijab by Islamic Posters (Accessed 22 February 2014). 